\title{
Marginal Adaptation of Indirect Restorations Using Different Resin Coating Protocols
}

\author{
Alberth David Correa MEDINA ${ }^{1}$ \\ Andréia Bolzan de PAULA ${ }^{1}$ \\ Suzana Beatriz Portugal de FUCIO $^{1}$ \\ Regina Maria PUPPIN-RONTANI² \\ Lourenço CORRER-SOBRINHO ${ }^{1}$ \\ Mário Alexandre Coelho SINHORETI ${ }^{1}$ \\ ${ }^{1}$ Department of Restorative Dentistry, Dental Materials Division, Piracicaba Dental School, \\ UNICAMP - University of Campinas, Piracicaba, SP, Brazil \\ ${ }^{2}$ Department of Pediatric Dentistry, Piracicaba Dental School, \\ UNICAMP - University of Campinas, SP, Brazil
}

\begin{abstract}
This study evaluated the influence of material combinations used in the resin coating technique (RCT) on the marginal adaptation of indirect restorations with gingival margins in enamel (EM) and cement (CM). Eighty third-molars were used. Two cavities were prepared in each tooth. The cavities were distributed into 16 groups. Cavities with EM were filled with the following material combinations: G1: Single-Bond 2 (Sb2), G2: Sb2 + Bond/Scotchbond-Multipurpose (Sb2B), G3: Sb2 + Filtek-Flow Z350 (Sb2F1), G4: ScotchbondMultipurpose (SBMP), G5: Clearfil-S3 (CS3), G6: CS3 + Bond/Clearfil-SE Bond (CSE3B), G7: CS3 + Protect Liner F (CS3PL) and G8: Clearfil SE Bond + Protect Liner F (CSEBPL). The same combinations were applied to the cavities in CM: G9, G10, G11, G12, G13, G14, G15, G16, respectively. The fillings were performed with the Sinfony-System (3M/ESPE). After 24 h, the teeth were submitted to thermocycling $\left(2,000\right.$ cycles, $5^{\circ}$ to $\left.55^{\circ} \mathrm{C}\right)$ and load-cycling $(50,000$ cycles, $50 \mathrm{~N})$. Next, the Caries-Detector (Kuraray) was applied to the restoration margins. Images from the proximal margin were evaluated using the Image-Tool 3.0 software. The results were submitted to ANOVA and Tukey's test $(\alpha=0.05)$. The mean values $(\%)$ for the groups were: $E M$ : $G 1=46.68, G 2=15.53$, $\mathrm{G} 3=19.83, \mathrm{G} 4=27.53 ; \mathrm{G} 5=59.49, \mathrm{G} 6=25.13, \mathrm{G} 7=34.37, \mathrm{G} 8=15.20 ; \mathrm{CM}: \mathrm{G} 9=38.38, \mathrm{G} 10=23.25, \mathrm{G} 11=26.97, \mathrm{G} 12=25.85, \mathrm{G} 13=37.81$, $\mathrm{G} 14=30.62, \mathrm{G} 15=29.17, \mathrm{G} 16=20.31$. The highest percentages of marginal gap on EM or CM were found in the groups that did not use a liner. It can be concluded that the most appropriate RCT combinations were the groups that used a liner.
\end{abstract}

Key Words: marginal adaptation, resin coating, adhesives, indirect restorations.

\section{INTRODUCTION}

Esthetic indirect composite restorations have been considered an excellent restorative alternative for extensive cavities. The process of fabrication of indirect restorations allows a good reproduction of the anatomic form and proximal contact in addition to limiting the polymerization shrinkage to a thin layer of luting cement used for cementation. On the other hand, this type of restoration demands a more invasive preparation, which may cause exposure of deep dentin and, consequently, pulp irritation. Clinical studies evaluating indirect restorations reported up to $30 \%$ of dentin hypersensitivity after the treatment (1). The resin coating technique (RCT) has been proposed in an attempt to minimize dentin hypersensitivity (2). This technique consists on the hybridization of the exposed dentin followed by the application of a hydrophobic monomer or a low viscosity resin, protecting the dentine exposed after the cavity preparation.

The stress caused by the polymerization shrinkage in indirect restorations is limited to the resin cement layer. The presence of a resin coating is believed to act as a layer absorbing the tensions originated by the polymerization shrinkage of the resin cement and the stress induced by occlusal load distributed during chewing, increasing the possibilities of clinical success of the restorations. A considerable reduction has been previously observed in the formation of microcracks at the tooth-restoration interface and an improvement

Correspondence: Prof. Dr. Mário Alexandre Coelho Sinhoreti, Departamento de Odontologia Restauradora, Faculdade de Odontologia de Piracicaba, UNICAMP, Avenida Limeira, 901, 13414-903 Piracicaba, SP, Brasil. Tel: +55-19-2106-5345. Fax: +55-19-2106-5218. e-mail: sinhoreti@fop.unicamp.br 
of the bond strength at the interface using the RCT $(3,4)$. Although the effectiveness of this technique was reported in several studies, few studies were performed considering factors like the cavity configuration and the stress caused by oral functions $(3,5)$, which could influence the long-term durability of the restorations $(6,7)$. Thermal and mechanical stresses, undergone by restorations in the oral environment, may be simulated in vitro using thermal and load cycling.

One way to predict the clinical success of the restorations in vitro is evaluating the marginal adaptation. Studies have shown that improvements in marginal adaptation might be achieved using the RCT $(3,5)$. However, little is known about the maintenance of the marginal adaptation when the restorations are submitted to stresses present in the clinical situation. Therefore, the aim of this study was to evaluate the influence of the combination of different materials used in RCT on the marginal adaptation of indirect restorations with margins in enamel and cement, after thermal and load cycling. The hypothesis tested was that the different associations of materials used for the resin coating influence the marginal adaptation of the indirect restorations.

\section{MATERIAL AND METHODS}

\section{Sample Preparation}

After approval of the research project by the institutional Ethics Committee (Protocol \#113/2005), 80 extracted third molars were collected, embedded in autopolymerizing acrylic resin (Clássico Produtos Odontológicos, São Paulo, SP, Brazil) inside polyvinyl chloride tubes (Tigre, Joinvile, SC, Brazil), leaving the cementoenamel junction (CEJ) located $2 \mathrm{~mm}$ above the acrylic resin. The periodontal ligament was reproduced applying a layer of polyether impression material (Impregum; 3M ESPE, AG Seefeld, Germany) over the roots. Two class II cavities were prepared in the same teeth using diamond burs (\#4137 KG; Sorensen, Barueri, SP, Brazil). The cavities had the following dimensions: 4 mm buccolingual width and $3 \mathrm{~mm}$ proximal-axial width. The gingival margin of the mesial cavity was located $1 \mathrm{~mm}$ below the CEJ (enamel margin - EM), while in the distal cavity the margin was located $1 \mathrm{~mm}$ above the CEJ (cement margin - CM). The dimensions and characteristics of the cavities are detailed in Figure 1. Cavities were randomly distributed in 16 groups $(\mathrm{n}=10)$, according to the material used to RTC and location of the margins to cavity. The materials used in each group and their composition are described in Table 1.

\section{Indirect Restoration Technique}

Impressions of the cavities were taken using putty and light body impression material (Aquasil; Dentsply DeTrey, Konstanz, Germany). A PVC cylinder (12.5 $\mathrm{mm}$ ) fixed to a metallic handle was used as an impression tray. After $1 \mathrm{~h}$, the casts were poured in stone (Durone IV; Dentsply Ind. e Com. Ltda., Petrópolis, RJ, Brazil) and removed after $60 \mathrm{~min}$. Indirect restorations, which were previously isolated with Isolacril (Asfer; São Paulo, SP, Brazil), were made on the stone with a composite Sinfony System (3M ESPE AG) using the incremental technique, starting with the proximal box followed by the occlusal box. Each increment was light-cured for $40 \mathrm{~s}$ using a quartz-tungsten-halogen light-curing unit (XL 2500; 3M ESPE, St. Paul, MN, USA) with light intensity of $500 \mathrm{~mW} / \mathrm{cm}^{2}$.
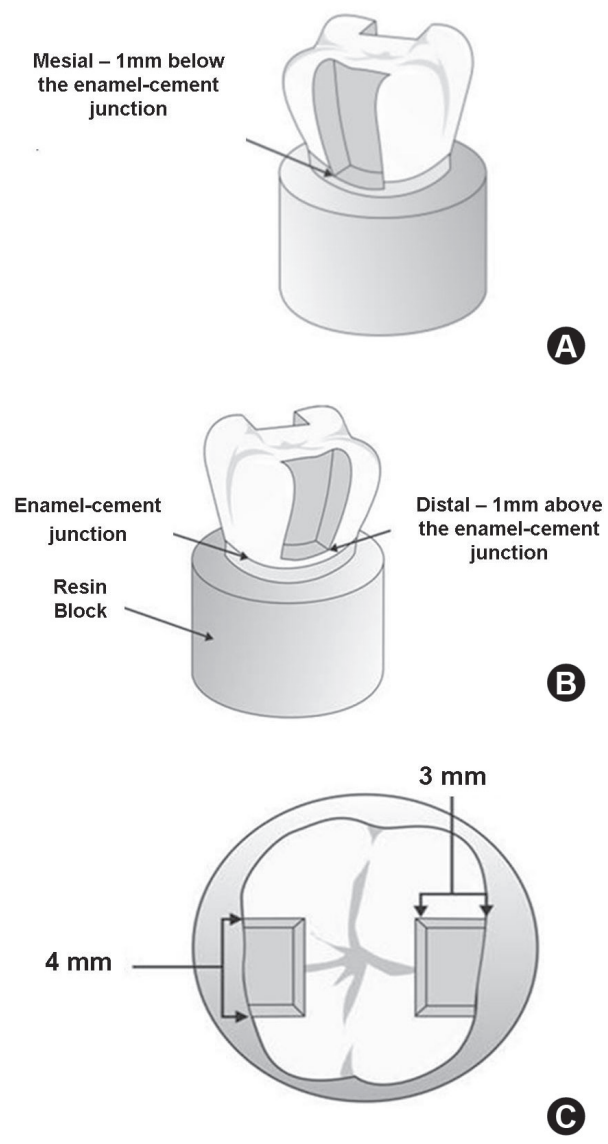

Figure 1. Characteristics and measurements of class II cavity. A: Mesial view. B: Distal view. C: Occlusal view of the cavity. 
Table 1. Materials used in this study.

\begin{tabular}{|c|c|c|}
\hline Materials & Composition & Manufacturer/Batch \# \\
\hline Single Bond 2 & $\begin{array}{l}\text { Water, ethanol, Bis-GMA, HEMA, UDMA, Bisphenol A glyceralote, } \\
\text { polyalkenoic acid copolymer, dimethacrylate, nanofiller }\end{array}$ & $\begin{array}{l}\text { 3M/ESPE. St. Paul, MN, USA } \\
\# 5 E P\end{array}$ \\
\hline $\begin{array}{l}\text { Scotch Bond } \\
\text { Multipurpose }\end{array}$ & $\begin{array}{l}\text { - Primer: HEMA, polyalkenoic acid copolymer } \\
\text { - Bond SBMP: Bis-GMA, HEMA, photoinitiator }\end{array}$ & $\begin{array}{l}\text { 3M/ESPE. St. Paul, MN, USA } \\
\text { \#5HP }\end{array}$ \\
\hline Filtek Flow & $\begin{array}{l}\text { FiltekFlow: Bis-GMA, TEGDMA, zirconia, } \\
\text { silica, camphorquinone, nanofilller }\end{array}$ & $\begin{array}{l}\text { 3M/ESPE. St. Paul, MN, USA } \\
\text { \#6031A2 }\end{array}$ \\
\hline Clearfil S3 & $\begin{array}{l}\text { MDP, Bis-GMA, HEMA, hydrophobic dimethacrylate, } \\
\text { photoinitiator, ethanol. }\end{array}$ & $\begin{array}{l}\text { Kuraray Medical, Tokyo, Japan } \\
\text { \# 00001A }\end{array}$ \\
\hline Protect Liner & $\begin{array}{l}\text { Bis-GMA,TEGDMA, fluoride methyl methacrylate, } \\
\text { camphorquinone, silanized colloidal silica. }\end{array}$ & $\begin{array}{l}\text { Kuraray Medical, Tokyo, Japan } \\
\text { F \# } 0046\end{array}$ \\
\hline
\end{tabular}

Bis-GMA: bisphenol-A diglycidyl ether dimethacrylate, HEMA: 2-hydroxyethyl methacrylate, MDP: 10-Methacryloyloxydecyl dihydrogen phosphate, TEGDMA: triethylene glycol dimethacrylate.

Table 2. Groups, materials and application technique.

\begin{tabular}{|c|c|c|c|}
\hline \multicolumn{2}{|c|}{ Group } & \multirow{2}{*}{ Material } & \multirow{2}{*}{ Application technique* } \\
\hline Enamel & Cement & & \\
\hline $\begin{array}{c}\mathrm{G} 1 \\
(\mathrm{Sb} 2)\end{array}$ & $\begin{array}{c}\text { G9 } \\
(\mathrm{Sb} 2)\end{array}$ & Single Bond 2 & $\mathrm{a}(15 \mathrm{~s}), \mathrm{b}(15 \mathrm{~s}), \mathrm{c}, \mathrm{d}, \mathrm{e}, \mathrm{d}, \mathrm{e}, \mathrm{l}(10 \mathrm{~s})$ \\
\hline $\begin{array}{c}\mathrm{G} 2 \\
(\mathrm{Sb} 2 \mathrm{~B})\end{array}$ & $\begin{array}{c}\mathrm{G} 10 \\
(\mathrm{Sb} 2 \mathrm{~B})\end{array}$ & $\begin{array}{c}\text { Single Bond } 2 \\
\text { Scotch Bond Multi Purpose }\end{array}$ & $\mathrm{a}(15 \mathrm{~s}), \mathrm{b}(15 \mathrm{~s}), \mathrm{c}, \mathrm{d}, \mathrm{e}, \mathrm{d}, \mathrm{e}, \mathrm{l}(10 \mathrm{~s}) \mathrm{k}, \mathrm{l}(10 \mathrm{~s})$ \\
\hline $\begin{array}{c}\mathrm{G} 3 \\
(\mathrm{Sb} 2 \mathrm{~F} 1)\end{array}$ & $\begin{array}{c}\mathrm{G} 11 \\
(\mathrm{Sb} 2 \mathrm{~F} 1)\end{array}$ & $\begin{array}{l}\text { Single Bond } 2 \\
\text { Filtek flow }\end{array}$ & $\begin{array}{c}\mathrm{a}(15 \mathrm{~s}), \mathrm{b}(15 \mathrm{~s}), \mathrm{c}, \mathrm{d}, \mathrm{e}, \mathrm{d}, \mathrm{e}, 1(10 \mathrm{~s}) \\
\text { Filtek Flow: i, } 1(20 \mathrm{~s})\end{array}$ \\
\hline $\begin{array}{c}\mathrm{G} 4 \\
(\mathrm{SBMP})\end{array}$ & $\begin{array}{c}\text { G12 } \\
(\mathrm{SBMP})\end{array}$ & Scotch Bond Multi Purpose & $\mathrm{a}(15 \mathrm{~s}), \mathrm{b}(15 \mathrm{~s}), \mathrm{c}, \mathrm{j}, \mathrm{e}, \mathrm{k}, \mathrm{l}(10 \mathrm{~s})$ \\
\hline $\begin{array}{c}\text { G5 } \\
(\mathrm{CS} 3)\end{array}$ & $\begin{array}{c}\mathrm{G} 13 \\
(\mathrm{CS} 3)\end{array}$ & Clearfil S3 & $\mathrm{h}(20 \mathrm{~s}), \mathrm{e}(5 \mathrm{~s}), \mathrm{l}(10 \mathrm{~s})$ \\
\hline $\begin{array}{c}\text { G6 } \\
(\mathrm{CS} 3 \mathrm{~B})\end{array}$ & $\begin{array}{c}\text { G14 } \\
(\mathrm{CS} 3 \mathrm{~B})\end{array}$ & $\begin{array}{l}\text { Clearfil S3 } \\
\text { Bond Clearfil SE Bond }\end{array}$ & $h(20 s), e(5 s), 1(10 s), g, e(5 s), 1(10 s)$ \\
\hline $\begin{array}{c}\mathrm{G} 7 \\
(\mathrm{CS} 3 \mathrm{PL})\end{array}$ & $\begin{array}{c}\mathrm{G} 15 \\
(\mathrm{SC} 3 \mathrm{PL})\end{array}$ & $\begin{array}{c}\text { Clearfil S3 } \\
\text { Protect Liner F }\end{array}$ & $\begin{array}{l}\text { h }(20 \mathrm{~s}), \mathrm{e}(5 \mathrm{~s}), 1(10 \mathrm{~s}) \\
\text { Protect Liner: } 1(20 \mathrm{~s})\end{array}$ \\
\hline $\begin{array}{c}\text { G8 } \\
(\mathrm{CSEBPL})\end{array}$ & $\begin{array}{c}\text { G16 } \\
(\mathrm{CSEBPL})\end{array}$ & $\begin{array}{l}\text { Clearfil SE Bond } \\
\text { Protect Liner F }\end{array}$ & $\begin{array}{l}f(20 \mathrm{~s}), \mathrm{e}, \mathrm{g}, \mathrm{e}(5 \mathrm{~s}), 1(10 \mathrm{~s}) \\
\quad \text { Protect Liner: } 1(20 \mathrm{~s})\end{array}$ \\
\hline
\end{tabular}

*a: acid etching; b: rinse the surface; c: dry with cotton-pellet; d: apply one layer total etch one step adhesive; e: gently air dry; f: apply primer of two-step self-etch adhesive; g: apply bond of two-step self-etch adhesive; h: apply one layer of self-etch one-step adhesive; i: apply one layer of resin flow; j: apply primer of three-step etch-and-rise adhesive, K: apply bond of three-step etch-andrise adhesive; l: light cure. 
The restorative procedure for the 16 groups was according to the RTC technique (Table 2).

\section{Cementation Procedures}

The cavities were etched with $35 \%$ phosphoric acid (3M ESPE AG) for $15 \mathrm{~s}$, water rinsed and air blasted to remove the excess water. Single Bond 2 (3M ESPE) was applied in a single layer and light-cured (XL2500; 3M ESPE) for $10 \mathrm{~s}$. The internal surfaces of the restorations were sandblasted with $50 \mu \mathrm{m} \mathrm{Al}_{2} \mathrm{O}_{3}$ powder at 2-bar pressure, treated with $35 \%$ phosphoric acid (3M ESPE AG) for $1 \mathrm{~min}$, and a silane layer (Ceramic Primer; 3M ESPE) was applied, left dry for $30 \mathrm{~s}$ and air thinned. A layer of Single Bond 2 was applied and light-cured for $10 \mathrm{~s}$. The dual cure resin luting agent Rely X ARC (3M ESPE) was applied on the internal surface of the restoration and inserted in the cavity preparation under finger pressure (8), simulating a clinical situation. The excess luting cement was removed with a cutting instrument. Then, each surface was light-cured for 40 $\mathrm{s}$. The restoration/tooth set was stored in $100 \%$ relative humidity at $37^{\circ} \mathrm{C}$ for $24 \mathrm{~h}$, followed by finishing with a fine and extra-fine grit diamond burs $(2135 \mathrm{~F}$ and 2135FF; KG Sorensen) and polished with a series of sandpaper disks (Sof-Lex; 3M ESPE).

\section{Thermo-mechanical Cycling Procedures}

After $24 \mathrm{~h}$ of storage followed by finishing and polishing, all specimens were subjected to a thermocycling regimen in a cycling machine (MSCT-3; Marcelo Nucci ME Instrument, São Carlos, SP, Brazil) totalizing 2,000 cycles in distilled water between 5 and $55^{\circ} \mathrm{C}$ with $30 \mathrm{~s}$ dwell time in each bath and transfer time of $10 \mathrm{~s}$ between baths. Next, all specimens were subjected to 250,000 fatigue cycles in the same machine, which consisted of cyclic loading with an $8 \mathrm{~mm}$ diameter stainless steel ball at $50 \mathrm{~N}$ load, immersed in distilled water $\left(37^{\circ} \mathrm{C}\right)$. The cyclic loading had a force profile in the form of a sine wave at $2 \mathrm{~Hz}$. Marginal adaptation was evaluated after the cycling procedures.

\section{Evaluation of Marginal Adaptation}

In order to evaluate the marginal adaptation of the restorations, a solution consisting of propylene glycol and acid red 52 Caries Detector (Kuraray Medical Inc., Okayama, Japan) was applied on the proximal surface of each restoration for $10 \mathrm{~s}$. The solution was washed and dried with absorbent paper. Two points were drawn on each tooth surface with a pen using a digital caliper at a distance of 2-mm. These points were used to calibrate the spatial measurement. In addition, a line was drawn on all tooth/restoration margins, and the tooth/ restoration total length was determined by adding the tooth surface lengths. Images of the proximal surface of the restorations were captured using a SLR Canon digital camera (Rebel XT; Lake Success, NY, USA) equipped with a $105 \mathrm{~mm}$ f2.8 lens Sigma Corporation (EXDG Macro, Kanagawa, Japan) and evaluated in the Image Tool 3.0 software (Periodontology Department, University of Texas Health Science Center, San Antonio, TX, USA). The software was used to measure the gap formation on the margin of the restoration (dentin or cement). All measurements were performed by the same investigator; the intraexaminer correlation was investigated with the Pearson's correlation test to $25 \%$ of the total sample. The total gap length was obtained by the sum of the dyed lengths of each surface. Data from each specimen were transformed to gap percentage in relation to the total margin using the following formula:

$$
\% \mathrm{GAP}=\frac{l \times 100}{l_{\mathrm{T}}}
$$

where $l$ is the dyed length and $l_{\mathrm{T}}$ is the total margin length (8). Data were analyzed by two-way ANOVA and Tukey's test $(\alpha=0.05)$.

\section{RESULTS}

All the groups presented marginal gap formation, either in EM or CM. Table 3 summarizes the results of dye penetration in EM and CM. Groups Sb2B (15.53\%) and CSEBPL (15.20\%) showed a significant reduction of gap formation in EM when compared with the other groups. The groups that did not use liner, Sb2 (36.68$46.68 \%$ ) and CS3 (59.49\%), showed the highest values of marginal gap. The highest gap formation in $\mathrm{CM}$ was obtained with the groups that did not use liner, $\mathrm{Sb} 2$ (35.38\% - 38.38\%) and CS3 (37.81\%) with statistically significant difference in relation the other groups. The other groups showed similar values.

\section{DISCUSSION}

The longevity of indirect composite restorations 
is influenced by physico-mechanical properties of the restoration and its luting cement. An adequate polymerization of resin cement is crucial to acquire optimal physical and biological properties and clinical performance $(9,10)$. Yet, the major factor in longevity is the bonding efficacy of the adhesives used in combination with the resin cement (11). The adhesive systems can increase the bond strength and improve the seal between a resin cement and tooth structure (12).

The results of the present study revealed statistically significant differences between the combinations of materials used for the RCT, confirming the tested hypothesis. Marginal adaptation is one of the most important aspects in indirect restorations, because it influences their longevity. It is well known that the cement layer is considerably challenged by the chewing load (13). A suitable alternative to reduce the stress produced by the masticatory forces and also by the polymerization shrinkage of the resin cement is the RCT, which may distribute the stress that would concentrate on the cement layer to the hybridized dentin and the liner material.

The present study focused on the type of materials used for the RCT. Due to constant and fast evolution of the dental materials, that do not allow evaluations by long-term clinical trials, mechanical and thermocycling were carried out allowing the simulation in vitro of what would happen in vivo $(14,15)$. Tests of thermal and load cycling have been frequently used in an attempt to simulate the fatigue of the restorations in oral environment. In theory, the fatigue resulting from the masticatory forces generates stresses at the tooth/

Table 3. Mean values (S.D.) of gap formation (\%) of indirect restorations with margin in enamel (EM) and cement $(\mathrm{CM})$.

\begin{tabular}{lcc}
\hline Resin coat & EM & CM \\
\hline Sb2 & $46.68(12.29) \mathrm{C}$ & $38.38(08.32) \mathrm{B}$ \\
$\mathrm{Sb} 2 \mathrm{~B}$ & $15.53(13.04) \mathrm{A}$ & $23.25(09.59) \mathrm{A}$ \\
$\mathrm{Sb} 2 \mathrm{~F} 1$ & $19.83(09.12) \mathrm{AB}$ & $26.97(06.32) \mathrm{A}$ \\
$\mathrm{SBMP}$ & $27.53(16.09) \mathrm{B}$ & $25.85(15.83) \mathrm{A}$ \\
$\mathrm{CS} 3$ & $59.49(09.18) \mathrm{C}$ & $37.81(07.43) \mathrm{B}$ \\
$\mathrm{CS} 3 \mathrm{~B}$ & $25.13(12.17) \mathrm{B}$ & $30.62(13.83) \mathrm{AB}$ \\
CS3PL & $34.37(13.24) \mathrm{B}$ & $29.17(12.38) \mathrm{A}$ \\
CSEBPL & $15.20(10.79) \mathrm{A}$ & $20.31(07.72) \mathrm{A}$ \\
\hline
\end{tabular}

Means followed by different uppercase letters in the same column indicate statistically significant difference (Tukey's test, $\mathrm{p}<0.05$ ). restoration interface, increasing the damages in this area $(7,16,17)$. Moreover, the temperature changes induce interfacial stresses due to differences of contraction and expansion between the tooth structures and the involved materials. These tensions may cause microcracks, which propagate throughout the adhesive interface and result in fluid percolation through the formed gap (18). Therefore, the thermo-mechanical simulation might provide results closer to the clinical situation.

Resin cements produce high levels of stress during polymerization (19). Furthermore, the incorporation of air bubbles during the manipulation of the cement weakens it and makes it more susceptible to fractures. The marginal gap observed in all groups might have resulted from these factors. Yet, the obtained results presented higher gap formation than previous studies (19), probably due to the stress of the thermal and load cycling. Still, it is suggested that other factors may have influenced these results in comparison with other studies, such as the type of preparation, the number of cycles and the load applied during cycling $(3,16,17)$.

It may be assumed that the sealing of dentin with a layer of hydrophobic monomer or a low viscosity composite could have absorbed part of the stress caused by the polymerization shrinkage of the cement or the load cycling, promoting better marginal adaptation $(3,4)$. The marginal adaptation may also have been influenced by the mechanical properties of the materials used for sealing, especially by the modulus of elasticity (20). Previous studies have shown that the use of liner (hydrophobic monomer or low viscosity resins), might potentially absorb the stress caused by the polymerization shrinkage and the masticatory forces $(21,22)$. Moreover, a more complete resin covering of collagen fibrils and residual spaces in the hybrid layer may have occurred due to a very low viscosity resin when compared to a relatively high viscosity of cement (23). This might have improved the quality of the hybrid layer and stability of marginal sealing and lower gap formation of the groups that used a liner, thus confirming the influence of this property on the marginal adaptation of the indirect restorations.

However, if the modulus of elasticity of the adhesive is low, it might not withstand the occlusal forces (24). This may explain the results observed in groups CS3 and $\mathrm{Sb} 2$, which received only a layer of adhesive without a liner (16). Another important factor in the marginal adaptation of restorations is the number of layers. Liner application avoid formation of the oxygen inhibited layer during polymerization and improved the degree 
of curing and consequently the mechanical properties, increasing the resistance to stress, compared with the groups that used only a coat of adhesive.

A high percentage of gap formation was observed in group CS3. This adhesive presents low viscosity, resulting in a thin adhesive layer. In the presence of oxygen, the polymerization of this layer may be limited, weakening the sealing of the tooth/restoration interface. Moreover, this adhesive is mainly constituted by hydrophilic monomers and solvent, which produce low cohesive resistance. As a result, the adhesive is unable to support the chewing stress (25).

Within the limitations of this study, it may be concluded that the groups that did not use liner showed a higher percentage of marginal gap. In addition, all indirect restorations presented marginal gap, independent of the material combinations used for resin coating.

\section{RESUMO}

Este estudo avaliou a influência de diferentes combinações de materiais usados na técnica de selamento dentinário (TSD) sobre a adaptação marginal de restaurações indiretas, cujas margens gengivais localizam-se em esmalte (ME) ou cemento (MC). Oitenta terceiros molares foram selecionados e duas cavidades foram preparadas em cada dente, as quais foram distribuídas em 16 grupos. As cavidades com margem em esmalte foram forradas pelas seguintes combinações de materiais: G1: Single-Bond2 (Sb2), G2: Sb2 + Bond/Scotchbond-Multipurpose (Sb2B), G3: Sb2 + Filtek-Flow Z350 (Sb2F1), G4: Scotchbond-Multipurpose (SBMP), G5: Clearfil-S3 (CS3), G6: CS3 + Bond/Clearfil-SE Bond (CSE3B), G7: CS3 + Protect Liner F (CS3PL), G8: Clearfil SE Bond + Protect Liner F (CSEBPL). As mesmas combinações foram aplicadas às cavidades com margens em cemento: G9, G10, G11, G12, G13, G14, G15, G16, respectivamente. As restaurações foram confeccionadas usando o sistema Sinfony (3M/ESPE). Após $24 \mathrm{~h}$, os dentes restaurados foram submetidos à ciclagem térmica ( 2.000 ciclos $-5^{\circ}$ a $\left.55^{\circ} \mathrm{C}\right)$ e mecânica $(50.000$ ciclos, $50 \mathrm{~N})$. Em seguida, Carie-Detector (Kuraray) foi aplicado sobre as margens das restaurações. As imagens obtidas da margem proximal foram avaliadas pelo software Image-Tool 3.0. Os resultados foram submetidos aos testes estatísticos ANOVA e Tukey $(p<0,05)$. As médias (\%) observadas para os grupos foram: ME: $\mathrm{G1}=46,68$, $\mathrm{G} 2=15,53, \mathrm{G} 3=19,83, \mathrm{G} 4=27,53 ; \mathrm{G} 5=59,49$, G6 $=25,13$, $\mathrm{G} 7=34,37$ e G8 $=15,20 ; \mathrm{MC}: \mathrm{G} 9=38,38, \mathrm{G} 10=23,25, \mathrm{G} 11=26,97$, $\mathrm{G} 12=25,85$, G13=37,81, G14=30,62, G15=29,17, G16=20,31. Os maiores valores de desadaptação marginal encontrados em ME e MC foram encontrados nos grupos que não utilizaram um "liner". Desta forma, pôde-se concluir que a combinação mais apropriada para a TSD é aquela que faz uso do "liner".

\section{ACKNOWLEDGEMENTS}

The authors would like to thank FAPESP - Fundação de Amparo a Pesquisa do Estado de São Paulo (Grant 05/59370-5) for the financial support to this project.

\section{REFERENCES}

1. Wassell R, Walls A, McCabe J. Direct composite inlays versus conventional composite restorations: three-year clinical results. Br Dent J 1995;179:343-349.

2. Satoh, M. How to use liner bond system as a dentin and pulp protector in indirect restorations. Jap J Adhes Dent 1994;12:41-47.

3. Jayasooriya PR, Pereira P, Nikaido T, Burrow MF, Tagami J. The effect of resin coating on the interfacial adaptation of composite inlays. Oper Dent 2003;28:28-35.

4. de Andrade OS, de Goes MF, Montes MA. Marginal adaptation and microtensile bond strength of composite indirect restorations bonded to dentin treated with adhesive and low-viscosity composite. Dent Mater 2007;23:279-287.

5. Kitayama S, Nasser NA, Pilecki P, Wilson RF, Nikaido T, Tagami J, et al.. Effect of resin coating and occlusal loading on microleakage of Class II computer-aided design/computer-aided manufacturing fabricated ceramic restorations: a confocal microscopic study. Acta Odontol Scand 2011;69:182-192.

6. Nikaido T, Kunzelmann KH, Chen H, Ogata M, Harada N, Yamagushi S, et al.. Evaluation of thermocycling and mechanical loading on bond strength of a self-etching primer system to dentin. Dent Mater 2002;18:269-275.

7. Shirai K, De Munck, Yoshida Y, Inoue S, Lambrechts V, Suzuki $\mathrm{K}$, et al.. Effect of cavity configuration and aging on the bonding effectiveness of six adhesives to dentin. Dent Mater 2005;21:110124.

8. Borges AFS, Correr GM, Sinhoreti MAC, Consani S, Sobrinho LC, Rontani RMP. Compressive strength recovery by composite onlays in primary teeth. Substrate treatment and luting agent effects. J Dent 2006;34:478-484.

9. de Paula AB, Tango RN, Sinhoreti MA, Alves MC, PuppinRontani RM. Effect of thickness of indirect restoration and distance from the light-curing unit tip on the hardness of a dualcured resin cement. Braz Dent J 2010;21:117-122.

10. Reges RV, Costa AR, Correr AB, Piva E, Puppin-Rontani RM, Sinhoreti MA, et al.. Effect of light-curing units, post-cured time and shade of resin cement on Knoop hardness. Braz Dent J. 2009;20:410-413.

11. Furukawa K, Inai N, Tagami J. The effects of luting resin bond to dentin on the strength of dentin supported by indirect resin composite. Dent Mater 2002;18:136-142.

12. Llena Puy MC, Forner Navarro L, Faus Llacer VJ, Ferrandez A. Composite resin inlays: a study of marginal adaptation. Quintessence Int 1993;24:429-433.

13. Ausiello P, Rengo S, Davidson CL, Watts DC. Stress distributions in adhesively cemented ceramic and resin-composite Class II inlay restorations: a 3D-FEA study. Dent Mater 2004;20:862-872.

14. Toledano M, Osorio R, Albaladejo A, Aguilera FS, Tay F, Ferrari M. Effect of cycling loading on the microtensile bond strenghts of total etch and self etch adhesives. Oper Dent 2006;31:25-32.

15. Braem MJ, Davidson CL, Lambrechts P, Vanherle G. In vitro flexural fatigue limits of dental composites. J Biomed Mater Res 1994;28:1397-1402.

16. Dietschi D, Olsburgh S, Krejci I, Davidson C. In vitro evaluation of marginal and internal adaptation after occlusal stressing of indirect class II composite restorations with different resinous bases. Eur J Oral Sci 2003;111:73-80.

17. Frankenberger R, Pashley DH, Reich SM, Lohbauer U, Petschelt A, Tay FR. Characterization of resin-dentine interfaces by compressive cyclic loading. Biomater 2005;26:2043-2052. 
18. Irie M, Suzuki K. Current luting cements: marginal gap formation of composite inlay and their mechanical properties. Dent Mater 2001;17:347-353.

19. Braga RR, Ferracane JL, Condon JR. Polymerization contraction stress in dual-cure cements and its effect on interfacial integrity of bonded inlays. J Dent 2002;30:333-340.

20. Montes MA, Goes MF, da Cunha MR, Soares AB. A morphological and tensile bond strength evaluation of an unfilled adhesive with low-viscosity composites and a filled adhesive in one and two coats. J Dent 2001;29:435-441.

21. Dietschi D, Bindi G, Krejci I, Davidson C. Marginal and internal adaptation of stratified compomer composite class II restorations Oper Dent 2002;27:500-509.

22. Sano H, Takatsu T, Ciucchi B, Horner J, Mattwhes W, Pashley D. Nanoleakage: leakage within the hybrid layer. Oper Dent 1995; 18:18-25.
23. Shafie F, Doozandeh M, Alavi A. Effect of resin coating and chlorhexidine on microleakage of two resin cements after storage. J Dent 2010;7:31-40.

24. Senawongse P, Pongprueksa P, Tagami J. The effect of the elastic modulus of low-viscosity resins on the microleakage of class $\mathrm{V}$ resin composite restorative under occlusal loading. Dent Mater J 2010;29:1-6.

25. Perdigão J, Dutra-Corrêa M, Castilhos N, Carmo AR, AnauateNetto C, Cordeiro HJ, et al.. One-year clinical performance of selfetch adhesives in posterior restorations. Amer J Dent 2007;20:125133.

Received March 2, 2012 Accepted August 21, 2012 